\title{
Volume of Distribution Predicted Normalized by Weight
}

National Cancer Institute

\section{Source}

National Cancer Institute. Volume of Distribution Predicted Normalized by Weight. NCI

Thesaurus. Code C92427.

The predicted volume of distribution associated with the terminal slope following intravascular administration divided by the weight. 